\begin{tabular}{|c|l|}
\hline Title & $\begin{array}{l}\text { Phy logenetic relationships among superfamilies of Cicadomorpha (Hemi ptera: A uchenorrhyncha) inferred from the } \\
\text { wing base structure }\end{array}$ \\
\hline Author(s) & Yoshizawa, Kazunori; Wagatsuma, Mutsumi \\
\hline Citation & $\begin{array}{l}\text { Entomological Science, 15(4), 408.421 } \\
\text { https://doi.org/40.1111/.1479-8298.2012.00528.x }\end{array}$ \\
\hline Issue Date & 2012-10 \\
\hline Doc URL & http://hdl.handle.net/2115/53418 \\
\hline Rights & The definitive version is available at wileyonlinelibrary.com \\
\hline Type & article (author version) \\
\hline File Information & ES15-4_408-421.pdf \\
\hline
\end{tabular}

Instructions for use 


\title{
Phylogenetic relationships among superfamilies of Cicadomorpha (Hemiptera: Auchenorrhyncha) inferred from the wing base
}

\section{structure}

\author{
Kazunori YOSHIZAWA and Mutsumi WAGATSUMA \\ Systematic Entomology, Graduate School of Agriculture, Hokkaido University, \\ Sapporo, Japan
}

\begin{abstract}
The infraorder Cicadomorpha is a monophyletic group of the order Hemiptera, suborder Auchenorrhyncha, and is composed of three superfamilies: Cercopoidea (spittle bugs), Cicadoidea (cicadas) and Membracoidea (leafhoppers and treehoppers). Phylogenetic relationships among the superfamilies have been highly controversial morphologically and molecularly, but recent molecular phylogenetic analyses provided support for Cercopoidea + Cicadoidea. In this study, we examined morphology of the wing base structure in Cicadomorpha and tested the previous phylogenetic hypotheses using the characters selected from the wing base. As a result, a sister-group relationship between Cicadoidea and Cercopoidea was supported by three synapomorphies (presence of a projection posterior to the anterior notal wing process, presence of a novel notal process anterior to the posterior notal wing process, presence of a novel sclerite between the distal median plate and the base of anal vein). The present study provides the first unambiguous and prominent morphological support for Cicadoidea + Cercopoidea.
\end{abstract}

Key words: Cercopoidea, Cicadoidea, Membracoidea, morphology, phylogeny.

\section{INTRODUCTION}

Cicadomorpha are an infraorder of the order Hemiptera (suborder Auchenorrhyncha) and are composed of three superfamilies: Cercopoidea (spittle bugs), Cicadoidea (cicadas) and Membracoidea (leafhoppers and treehoppers). The infraorder can be clearly distinguished from the other hemipterans morphologically (e.g. Dietrich 2005; Grimaldi \& Engel 2005), and its monophyly has been recognized consistently (Dietrich 2002; Cryan 2005; Forero 2008; Cryan \& Urban 2012). Monophyly of three cicadomorphan superfamilies has also been supported morphologically and molecularly (Evans 1963; Blocker 1996; Cryan 2005; Cryan \& Urban 2012).

Phylogenetic relationships among the superfamilies, in contrast, have been highly controversial (see Bourgoin \& Campbell 2002; Cryan 2005; Forero 2008). This problem has also been challenged using molecular data, but earlier attempts failed to provide a reliable conclusion. For example, using $18 S$ rDNA sequences, von Dohlen and Moran (1995) and Sorensen et al. (1995) provided support for Cercopoidea + Membracoidea, whereas, using the same gene marker, Campbell et al. (1995) and Ouvrard et al. (2000) provided Cicadoidea + Cercopoidea. Cryan (2005) claimed that the widely used $18 S$ might not be a suitable marker in resolving this problem. Recently, Cryan (2005) and Cryan and Urban (2012) finally provided support for Cicadoidea + Cercopoidea with high support values based on extensive taxon sampling and multiple gene sequences.

However, morphology-based phylogeny is far from convincing, and all three possible relationships are still plausible (reviewed in Cryan 2005 and Forero 2008): i.e. Cicadoidea + Membracoidea (Evans 1963; Hamilton 1996, 1999), Cercopoidea + Membracoidea (Hamilton 1981; Blocker 1996) or Cicadoidea + Cercopoidea (Liang \& Fletcher 2002; Rakitov 2002). Cicadoidea + Cercopoidea, the relationship congruent with the latest molecular 
phylogeny, has also been suggested from the structures of antennae (Liang \& Fletcher 2002) and the Malpighian tube (Rakitov 2002). However, this relationship was suggested based on limited taxon sampling without quantitative analysis (Liang \& Fletcher 2002; Rakitov 2002) or even based solely on "similarity" (i.e. polarity of the similarities has not been tested based on outgroup comparison, Liang \& Fletcher 2002). Therefore, morphology-based phylogenetic analysis using different and reliable character systems with wider taxon sampling is still desired in testing the phylogenetic hypotheses of Cicadomorpha (Cryan 2005; Cryan \& Urban 2012).

The wing base structure consists of the lateral notal margin, three axillary sclerites, two median plates and the bases of the wing veins. The structure is known to evolve very slowly and consists of many sclerites with complicated articulations (Hörnschemeyer 2002; Hörnschemeyer \& Willkommen 2007). Therefore, a number of characters can be coded from the structure; these are useful for higher level phylogenetic estimation (Yoshizawa 2011). Yoshizawa and Saigusa (2001) applied the characters selected from the wing base for recovering the ordinal and infraordinal phylogeny of Paraneoptera, including the hemipteran infraorders. At that time, most morphological (Hamilton 1981; Bourgoin 1986a, b, 1993; Wootton \& Betts 1986; Bourgoin \& Huang 1990) and molecular (Campbell et al. 1995; Sorensen et al. 1995; Bourgoin et al. 1997; Ouvrard et al. 2000; Xie et al. 2008) studies suggested paraphyly of Auchenorrhyncha (hemipteran infraorder including Cicadomorpha and Fulgoromorpha). However, phylogenetic analysis based on the wing base characters clearly showed that the infraorder is monophyletic (Yoshizawa \& Saigusa 2001). Recent molecular analyses based on multiple gene markers (Cryan \& Urban 2012) provided strong support for Auchenorrhyncha, corroborating the significance of the wing base structure for the higher-level systematics of Hemiptera.

In this study, we examined the fore- and hindwing base structures of Cicadomorpha and, using the characters selected from the wing base, phylogenetic relationships among the cicadomorphan superfamilies were estimated.

\section{MATERIALS AND METHODS}

Taxa examined are listed in Table 1. Dried specimens or specimens stored in $80 \%$ ethanol were used. Methods for preparation, observation and illustration followed Yoshizawa (2011). Vouchers are deposited in the Hokkaido University Insect Collection. Terminology followed Yoshizawa and Saigusa (2001). The following abbreviations were used in the text and figures: anterior, median, posterior notal wing processes = ANWP, MNWP, PNWP; pseudo-PNWP = pPNWP (see below); first, second, third axillary sclerites $=1 \mathrm{Ax}, 2 \mathrm{Ax}, 3 \mathrm{Ax}$; proximal, distal median plates $=\mathrm{PMP}$, $\mathrm{DMP}$; tegula $=\mathrm{Tg}$; humeral plate $=\mathrm{HP}$; basisubcostale $=\mathrm{BSc}$; basiradiale $=\mathrm{BR}$; basanale $=$ BA. In the figures, the numbers followed by a bracket indicate the character number, and the numbers in the brackets indicate state of the character.

Both fore- and hindwing base structures were subjected for character coding. As mentioned previously (Yoshizawa \& Saigusa 2001; Ninomiya \& Yoshizawa 2009; Yoshizawa 2011), fore- and hindwing base structures usually show analogous modifications when both wings are homogeneous in shape (e.g. Odonata, Plecoptera, Psocodea etc.). In such cases, use of both wings for character coding may cause double counting of a single character and thus should be avoided. However, fore- and hindwings of hemipterans are significantly different in shape and function, and their basal structures also show differences in general. Therefore, use of both wings may be justified. In contrast, similar trends were also identified for sometimes between foreand hindwing base modifications. Therefore, the characters were coded according to the following categories. Fore- or hindwing: modifications restricted to one of two wings, for which each modification occurring on different wing was coded separately; foreand hindwings: modifications observed in both wings, for which modifications on both 
wings were treated as a single character. Detailed discussions were also given in the character list.

For phylogenetic analysis, each family was treated as a terminal taxon for ingroups. When a character was variable within a family, it was coded as a variable character (i.e. $0 / 1$ ). Quantitative characters were not coded unless variation was not continuous and could be coded clearly. Outgroups were selected from Fulgoromorpha (sister taxon of Cicadomorpha) and Heteroptera (one of the sister taxa of Auchenorrhyncha) (Yoshizawa \& Saigusa 2001; Cryan \& Urban 2012), and these higher taxa were treated as terminals. PAUP* 4.0b10 software (Swofford 2002) was used for cladistic analysis, with the branch-and-bound search option. Trees were rooted with Heteroptera. The Bremer support value was calculated using TreeRot3 software (Sorenson \& Franzosa 2007). The character state changes and the consistency and retention indices were calculated using MacClade 4 software (Maddison \& Maddison 2001). The data matrix is shown in Table 2 and is also available online as a Supplementary file (in nexus format).

\section{RESULTS}

\section{Morphology of forewing base (Figs 1-10)}

The general morphology of the auchenorrhynchan forewing base structure was described by Yoshizawa and Saigusa (2001), in which the criteria and landmarks for homology identification of each structure were also explained. The absence of tegula has been recognized as one of the autapomorphies of Cicadomorpha (e.g. Dietrich 2005; Grimaldi \& Engel 2005), but we detected the weakly sclerotized tegula throughout the taxa examined (see also Yoshizawa \& Saigusa 2001). Therefore, the absence of tegula should be excluded from the autapomorphies of the infraorder.

The present examination identified the following variations in the forewing base structure among the taxa examined. Character length (1), consistency index (ci) and retention index (ri) calculated on the optimized trees (see Phylogenetic Analysis section) were also noted.

Character 1. Anterodistal corner of HP: smoothly rounded (0); acutely pointed (1). $1=1$, $\mathrm{ci}=1, \mathrm{ri}=0$. State 1 only but consistently observed in Cicadidae (Cicadoidea: Fig. 2).

Character 2. Posterodistal corner of HP: no swelling (0); with swelling (1). 1=1, ci=1, $\mathrm{ri}=1$. State 1 was observed in Cicadoidea (Figs 1,2).

Character 3. ANWP: without posterior projection (0); with posterior projection fitting into concavity of $1 \mathrm{Ax}$ when wings are closed (1). $1=1$, ci $=1$, ri $=1$. State 1 was observed in Cicadoidea (Figs 1,2) and Cercopoidea (Figs 3-5). Detailed condition of the closed wing is explained in Figure 9.

Character 4. Distal margin of DMP1: no swelling (0); with strong swelling overlapping DMP2 (1). $1=1$, ci=1, ri=1. State 1 was observed in Cicadellidae (Fig. 6) and Membracidae (Fig. 7) (Membracoidea).

Character 5. Anterodistal corner of DMP1: no tubercle (0); with tubercle (1). $1=1$, $\mathrm{ci}=1, \mathrm{ri}=1$. State 1 was observed in Cicadoidea (Figs 1,2).

Character 6. Sclerite posterior to DMP1: absent (0); present (1). $1=1, \mathrm{ci}=1, \mathrm{ri}=1$. State 1 was observed in all three superfamilies. See Figure 10 and discussion under Character 7 for detailed discussion on homologization.

Character 7. Sclerite distal to Character 6[1]: absent (0); present (1). $1=1, \mathrm{ci}=1, \mathrm{ri}=1$. State 1 was observed in Cicadoidea (Figs 1,2) and Cercopoidea (Figs 3-5). In some taxa examined, one or two small sclerites were observed posterior to DMP1. Judging from their relative positions, they may be interpreted as PMP. DMP and PMP are separated along the convex axillary fold line (Wootton 1979; Yoshizawa \& 
Saigusa 2001). However, this line runs posterior to the small sclerites (e.g. Fig. 2). Therefore, the sclerites can not be homologized with PMP and should be regarded as newly derived sclerites. As seen from Figure 10, the sclerite coded as Character 6[1] is tightly associated with DMP1 whereas the sclerite coded as Character 7[1] is tightly associated with the base of the anal vein. Based on this difference, homology of two sclerites can be identified clearly.

Character 8. DMP2: small (0); enlarged (1). $1=2$, $\mathrm{ci}=0.5, \mathrm{ri}=0.5$. This is a quantitative character that may involve ambiguity for character coding. When DMP2 is significantly smaller than $2 \mathrm{Ax}$, that was regarded as small (state 0 : Figs 2,7), and DMP2 is about the same size with or larger than $2 \mathrm{Ax}$, which was considered to be enlarged (state 1). State 1 was widely observed throughout Cicadomorpha but, in Cicadidae (Cicadoidea: Fig. 2) and some species of Membracidae (Membracoidea: Fig. 7), DMP2 is apparently smaller than $2 \mathrm{Ax}$.

Character 9. PNWP: present $(0)$; absent $(1) .1=2$, ci $=0.5, \mathrm{ri}=0.5$. State 1 was observed in Cicadellidae, Membracidae (Figs 6,7: Membracoidea) and Aphrophoridae (Fig. 5: Cercopoidea). See also explanation under Character 15.

Character 10. Jugum: well developed (0); reduced or absent (1). $1=1, \mathrm{ci}=1, \mathrm{ri}=1$. This is a quantitative character, but there was no ambiguity to separate two states of this character (e.g. see Figs 1,3). State 1 was widely observed throughout the ingroups and outgroups, but state 0 was observed in Cicadoidea (Figs 1,2), Heteroptera and some fulgoromorphans (Fig. 8).

\section{Morphology of hindwing base (Figs 1-8)}

The hindwing base structure of Auchenorrhyncha is superficially very different from that of the forewing but consists of the fundamental sclerites as observed in the forewing base. Therefore, homology identification could be done based on the criteria and landmarks as used for the homologization of the forewing base sclerites (Yoshizawa \& Saigusa 2001). The apomorphies commonly observed in the paraneopteran (e.g. reduction of the head and neck of $1 \mathrm{Ax}$, fusion of BSc and $2 \mathrm{Ax}$, bulged anterior region of $2 \mathrm{Ax}$ etc.) or auchenorrhynchan (i.e. absence of PMP: Yoshizawa \& Saigusa 2001) forewing base were also identified in the hindwing base. Some significant differences between the fore- and hindwing bases are as follows (conditions observed in the forewing are noted in the parentheses): PNWP almost always absent (absent for limited taxa); HP not tightly fused with BSc (tightly fused); DMP undivided (divided into two sclerites); BA fused with 3Ax (articulated). However, these were uniformly observed throughout the taxa examined and thus were not coded for the analysis.

In addition to the above points, the present examination identified the following modifications among the taxa examined.

Character 11. Anterolateral region of notum: not separated (0); separated from median and posterior regions (1). $1=2, \mathrm{ci}=0.5, \mathrm{ri}=0.5$. State 1 was observed in Membracidae (Membracoidea: Fig. 7) and Cercopoidea (Figs 3-4). However, in some species of Aphrophoridae (Cercopoidea), the lateral notal plate is only partly separated from the other regions (Fig. 5). Therefore, state $0 / 1$ was given for the family.

Character 12 . Notum and 3Ax: widely separated by membrane (0); tightly articulated (1). $1=1, \mathrm{ci}=1, \mathrm{ri}=1$ (topology 1 ); $1=2, \mathrm{ci}=0.5, \mathrm{ri}=0.5$ (topology2). State 1 was observed in Machaerotidae, Cercopidae (Cercopoidea: Figs 3,4) and some species of Membracidae (Membracoidea: Fig. 7).

Character 13. 1Ax: present (0); absent (1). $1=1, \mathrm{ci}=1, \mathrm{ri}=1$. State 1 was clearly and consistently observed throughout Cercopoidea (Figs 3-5). This is a very peculiar modification never observed before (e.g. Yoshizawa \& Saigusa 2001; Hörnschemeyer 2002; Hörnschemeyer \& Willkommen 2007; Yoshizawa \& 
Ninomiya 2007; Ninomiya \& Yoshizawa 2009; Yoshizawa 2011). Because 1Ax is an important sclerite in mediating thoracic movements to the wing veins (Brodsky 1994), the functional aspect of this modification is also very interesting.

\section{Modifications occurring in both wings (Figs 1-8)}

The following characters were variable among the taxa examined, and modifications were observed in both the fore- and hindwing bases.

Character 14. BSc-2Ax fusion: almost entirely fused (0); only partly fused (1). $1=1$, $\mathrm{ci}=1, \mathrm{ri}=1$. The character state 0 was observed throughout the paraneopteran outgroups (Yoshizawa \& Saigusa 2001), and state 1 was only observed in Cicadoidea (Figs 1,2) among the ingroups.

Character 15. Pseudo-PNWP: absent (0); present (1). $1=1$, ci $=1$, ri $=1$. State 1 of this character was observed in Cicadoidea and Cercopoidea (Figs 1-5). pPNWP is considered here as a de novo structure which occurs anterior to PNWP and articulates with the posterior arm of $3 \mathrm{Ax}$ along the basal hinge. In the forewings of Tettigarctidae, Cicadidae (Cicadoidea: Figs 1,2), Machaerotidae and Cercopidae (Cercopoidea: Figs 3,4), two sclerites are extended from the notum and articulated with $3 \mathrm{Ax}$ along the basal hinge: one apparently represents the true PNWP extending from the posterior corner of the notum, and the other one is termed and homologized here as the pseudo-PNWP. In these groups, pPNWP is placed far distant from the posterior end of the notum. In some cases (e.g. Aphrophoridae: Cercopoidea: Fig. 5), 3Ax articulates only with pPNWP in the forewing, and true PNWP was considered to be completely absent (Character 9[1]). Therefore, their homology identification contains some difficulties. When $3 \mathrm{Ax}$ articulates proximally with the process arising distantly from the posterior margin of the notum, the process was homologized as pPNWP (Fig. 5). In addition to the homology identification, distribution of the character state 1 is complicated, i.e. present in both wing bases in Tettigarctidae, Cicadidae (Cicadoidea: Figs 1,2) and Aphrophoridae (Cercopoidea: Fig. 5), or present only in the forewing base in Machaerotidae and Cercopidae (Cercopoidea: Figs 3,4). Therefore, it causes difficulty in character coding. However, pPNWP is apparently a de novo character never observed in the outgroups, and its occurrence can be considered as a single gain character. In the cases of the hindwing of Machaerotidae and Cercopidae (Cercopoidea), 3Ax articulates directly with the notal margin (Figs 3,4). This apparently represents a derived condition (Character 12[1]) so that, in these cases, secondary reduction of pPNWP is also highly plausible. Therefore, we treated the presence or absence of pPNWP as a fore- and hindwing base character and coded state 1 for this character when pPNWP occurs at least one of two wings. A superficially similar sclerite was also observed in the forewing of some Fulgoromorpha (Tettigometridae and Cixiidae, Fig. 8), but the sclerite is located outer to the basal hinge, whereas pPNWP is located internal to the hinge line (Figs 1-5). Therefore, they clearly represent different structures.

Character 16. Condition of pPNWP: separated from notum (0); fused with notum (1). $1=2, \mathrm{ci}=0.5, \mathrm{ri}=0 \quad($ topology 1$) ; 1=1, \mathrm{ci}=1, \mathrm{ri}=1$ (topology2). State 1 was observed in Machaerotidae and Aphrophoridae (Cercopoidea: Figs 3,5). The state of this character was treated as unknown (?) for Membracoidea and outgroups because of lack of pPNWP (Figs 6-8). Although state 1 was only observed in the forewing, this character is listed here in relation to Character 15.

\section{Phylogenetic analysis}

Phylogenetic analysis of the data set coded from the wing base characters (Table 2) provided two equally parsimonious trees, both with $\mathrm{L}=20, \mathrm{CI}=0.80$ and $\mathrm{RI}=0.84$ 
(Fig. 11). Three autapomorphies of Cicadomorpha were detected (Bremer support value $[\mathrm{BS}]=2$ ), of which one was non-homoplasious (Character 6). Monophyly of all three superfamilies was supported: Membracoidea by two autapomorphies $(\mathrm{BS}=2)$ with a non-homoplasious one (Character 4), Cicadoidea by four autapomorphies $(\mathrm{BS}=4)$ with three non-homoplasious ones (Characters 2, 5 and 14), and Cercopoidea by one to three autapomorphies $(\mathrm{BS}=1)$, with a non-homoplasious one (Character 13). Within the Cicadomorpha, Membracoidea were sister to a clade comprising Cicadoidea and Cercopoidea $(\mathrm{BS}=3)$. Synapomorphies supporting Cicadoidea + Cercopoidea are the presence of the posterior projection of ANWP (Character 3[1]), presence of two sclerites posterior to DMP1 (Character 7[1]) and presence of pseudo-PNWP (Character 15[1]) (Figs 1-5,9,10): all of these non-homoplasious. More than two families were sampled from Cercopoidea, and the difference of two topologies concerned the relationships among cercopoid families. Topologyl (Fig. 11) supported Machaerotidae + Cercopidae with two homoplasious characters (Characters 11 and 12). Topology2 (Fig. 11) supported Machaerotidae + Aphrophoridae with a nonhomoplasious Character 16.

\section{DISCUSSION}

By the present phylogenetic analysis based solely on the wing base characters, all the cicadomorphan superfamilies were recovered to be monophyletic, and new autapomorphies for Cicadomorpha were also identified (Fig. 11). These results are in agreement with the traditional and molecular phylogenies, for which consensus has been well established (e.g. Cryan 2005; Forero 2008). This shows that the wing base structure contains useful phylogenetic signals for recovering the superfamily-level phylogeny of Hemiptera.

Most importantly, the present analysis yielded the trees supporting Cicadoidea + Cercopoidea (Fig. 11). This result is concordant with the recent molecular phylogenetic analyses based on multiple gene markers with extensive taxon sampling (Cryan 2005; Cryan \& Urban 2012). In contrast, morphological support for this relationship is still debatable (Cryan 2005; Forero 2008). Three synapomorphies of Cicadoidea and Cercopoidea detected from the wing base are all gain characters, not homoplasious, and highly complicated in modifications (Figs 1-5,9,10). In contrast, two characters were identified to contradict to the result and support Cercopoidea + Membracoidea (Characters 11[1] and 12[1]). However, these character states were only observed in limited members of the superfamily Membracoidea and also variable within a family (i.e. 11[0/1] for Aphrophoridae and 12[0/1] for Membracidae). Therefore, these are far less reliable characters than those supporting Cicadoidea + Cercopoidea. Additional morphological characters supporting Cicadoidea + Cercopoidea have also been identified previously: the similarity of antennal character (Liang \& Fletcher 2002 but note that polarity of the similarity has not been tested) and modification of the Malpighian tubes in nymphs (Rakitov 2002). Given the morphological support from the independent character systems, the sister group relationship between Cicadoidea and Cercopoidea can now be regarded as robust morphologically, as well as molecularly (Cryan 2005; Cryan \& Urban 2012).

In contrast, the present analysis also provided apparently contradicting results with the results from the molecular analyses. In the present trees, either Machaerotidae + Cercopidae (Fig. 11, topology1) or Machaerotidae + Aphrophoridae (Fig. 11, topology2) was supported within Cercopoidea whereas, in the molecular trees, a closer relationship between Cercopidae and Aphrophoridae is supported with high support values (Cryan 2005; Cryan \& Urban 2012). However, support from the wing base for the relationships within Cercopoidea was weak (Bremer support value $=0$ for both topologies) and thus the results from the wing base are less reliable.

In conclusion, the characters selected from the wing base structure provided a highly 
resolved phylogenetic tree of Cicadomorpha that is well congruent with the molecular trees. The sister-group relationship between Cicadoidea + Cercopoidea can be now considered as receiving strong support morphologically and molecularly.

\section{ACKNOWLEDGMENTS}

We thank Masami Hayashi and Shigeyuki Koshikawa for giving us valuable specimens for this study. This study was in part conducted as MW's Master thesis. MW thanks Takuma Yoshida and Ryuta Takayanagi for help in sampling, Shin-ichi Akimoto, Masahiro Ôhara and other members of the laboratory of Systematic Entomology, Hokkaido University for valuable suggestions.

\section{REFERENCES}

Blocker HD (1996) Origin and radiation of the Auchenorrhyncha. In: Schaefer CW (ed.) Studies on Hemipteran Phylogeny, pp 46-64. Proceedings, Thomas Say Publications in Entomology. Entomological Society of America, Lanham.

Bourgoin T (1986a) Morphologie imaginale du tentorium des Hemiptera

Fulgoromorpha. International Journal of Insect Morphology and Embryology 15, 237-252.

Bourgoin T (1986b) ) Valeur morphologique de la lame maxillaire chez les Hemiptera. Remarques phylogénétiques. Annales de la Société Entomologique de France (N.S.) 22, 413-422.

Bourgoin T (1993) Female genitalia in Hemiptera Fulgoromorpha, morphological and phylogenetic data. Annales de la Société Entomologique de France (N.S.) 29, 225-244.

Bourgoin T, Campbell BC (2002) Inferring a phylogeny for Hemiptera: falling into the "autapomorphic" trap. Denisia 4, 67-82.

Bourgoin T, Huang J (1990) Morphologie comparée des genitalia mâles des

Trypertimorphini et remarques phylogé- nétiques (Hemiptera: Fulgoromoprha:

Tropiduchidae). Annales de la Société Entomologique de France (N.S.) 26, 555564.

Bourgoin T, Steffen-Campbell JD, Campbell BC (1997) Molecular phylogeny of

Fulgoromorpha (Insecta, Hemiptera, Archaeorrhyncha). The enigmatic

Tettigometridae: evolutionary affiliations and historical biogeography. Cladistics 13, 207-224.

Brodsky AK (1994) The Evolution of Insect Flight. Oxford University Press, Oxford. Campbell BC, Steffen-Campbell JD, Sorensen JT, Gill RJ (1995) Paraphyly of

Homoptera and Auchenorrhyncha inferred from 18S rDNA nucleotide sequences. Systematic Entomology 20, 175-194.

Cryan JR (2005) Molecular phylogeny of Cicadomorpha (Insecta: Hemiptera:

Cicadoidea, Cercopoidea and Membracoidea): adding evidence to the controversy. Systematic Entomology 30, 563-574.

Cryan JR, Urban JM (2012) Higher-level phylogeny of the insect order Hemiptera: is Auchenorrhyncha really paraphyletic? Systematic Entomology 37, 7-21.

Dietrich CH (2002) Evolution of Cicadomorpha (Insecta, Hemiptera). Denisia 4, 155170.

Dietrich CH (2005) Keys to the families of Cicadomorpha and subfamilies and tribes of Cicadellidae (Hemiptera: Auchenorrhyncha). Florida Entomologist 88, 502- 


\section{7.}

Evans JW (1963) The phylogeny of the Homoptera. Annual Review of Entomology 8, $77-94$.

Forero D (2008) The systematics of the Hemiptera. Revisía Colombiana de Entomología 34, 1-21.

Grimaldi D, Engel MS (2005) Evolution of the Insects. Cambridge University Press, New York.

Hamilton KGA (1981) Morphology and evolution of the Rhynchotan head (Insecta: Hemiptera, Homoptera). The Canadian Entomologist 113, 953-974.

Hamilton KGA (1996) Cretaceous Homoptera from Brazil: implications for classification. In: Schaefer CW (ed.) Studies on Hemipteran Phylogeny, pp 89110. Proceedings, Thomas Say Publications in Entomology. Entomological Society of America, Lanham.

Hamilton KGA (1999) The ground-dwelling leafhoppers Myerslopiidae, new family, and Sagmatiini, new tribe (Homoptera: Membracoidea). Invertebrate Taxonomy 13, 207-235.

Hörnschemeyer T (2002) Phylogenetic significance of the wing-base of the Holometabola (Insecta). Zoologica Scripta 31, 19-27.

Hörnschemeyer T, Willkommen J (2007) The contribution of flight system characters to the reconstruction of the phylogeny of the Pterygota. Arthropod Systematics and Phylogeny 65, 15-23.

Liang AP, Fletcher MJ (2002) Morphology of the antennal sensilla in four Australian spittlebug species (Hemiptera: Cercopidae) with implications for phylogeny. Australian Journal of Entomology 41, 39-44.

Maddison DR, Maddison WP (2001) MacClade 4: Analysis of Phylogeny and Character Evolution. Sinauer, MA.

Ninomiya T, Yoshizawa K (2009) A revised interpretation of the wing base structure in Odonata. Systematic Entomology 34, 334-345.

Ouvrard D, Campbell BC, Bourgoin T, Chan KL (2000) 18S rRNA secondary structure and phylogenetic position of Peloridiidae (Insecta, Hemiptera). Molecular Phylogenetics and Evolution 16, 403-417.

Rakitov RA (2002) Structure and function of the Malpighian tubules, and related behaviors in juvenile cicadas: evidence of homology with spittlebugs (Hemiptera: Cicadoidea and Cercopoidea). Zoologischer Anzeiger 241, 117130.

Sorensen JT, Campbell BC, Gill RJ, Steffen-Campbell JD (1995) Non-monophyly of Auchenorrhyncha ("Homoptera"), based upon 18S rDNA phylogeny: ecoevolutionary and cladistic implications within pre-Heteropterodea Hemiptera (s.l.) and a proposal for new monophyletic suborders. Pan-Pacific Entomologist 71, 31-60.

Sorenson MD, Franzosa EA (2007) TreeRot, Version 3. Boston University, Boston, MA.

Swofford DL (2002) PAUP*. Phylogenetic Analysis Using Parsimony (* and Other Methods), Version 4. Sinauer, MA.

von Dohlen CD, Moran NA (1995) Molecular phylogeny of the Homoptera: a paraphyletic taxon. Journal of Molecular Evolution 41, 211-223. 
Wootton RJ (1979) Function, homology and terminology in insect wings. Systematic Entomology 4, 81-93.

Wootton RJ, Betts CR (1986) Homology and function in the wings of Heteroptera. Systematic Entomology 11, 389-400.

Xie Q, Tian Y, Zheng L, Bu W (2008) 18S rRNA hyper-elongation and the phylogeny of Euhemiptera (Insecta: Hemiptera). Molecular Phylogenetics and Evolution 47, 463-471.

Yoshizawa K (2011) Monophyletic Polyneoptera recovered by the wing base structure. Systematic Entomology 36, 377-394.

Yoshizawa K, Ninomiya T (2007) Homology of the wing base structure in Ephemeroptera (Insecta: Pterygota) - a reply to Willkommen and Hörnschemeyer. Arthropod Structure and Development 36, 277-279.

Yoshizawa K, Saigusa T (2001) Phylogenetic analysis of paraneopteran orders (Insecta: Neoptera) based on forewing base structure, with comments on monophyly of Auchenorrhyncha (Hemiptera). Systematic Entomology 26, 1-13.

\section{SUPPORTING INFORMATION}

Additional Supporting Information may be found in the online version of this article:

Appendix S1. Data matrix used for the cladistic analysis (in nexus format). See text for characters and their states. Please note: Wiley-Blackwell is not responsible for the content or functionality of any supporting materials supplied by the authors. Any queries (other than missing material) should be directed to the corresponding author for the article.

Figure 1 Fore- (top) and hindwing (bottom) base structures of Tettigarcta crinita (Cicadoidea: Tettigarctidae). Numbers followed by a bracket indicate the character number, and the numbers in the brackets indicate state of the character.

Figure 2 Fore- (top) and hindwing (bottom) base structures of Meimuna opalifera (Cicadoidea: Cicadidae).

Figure 3 Fore- (top) and hindwing (bottom) base structures of Hindoloides bipunctata (Cercopoidea: Machaerotidae).

Figure 4 Fore- (top) and hindwing (bottom) base structures of Cosmoscarta sp. (Cercopoidea: Cercopidae).

Figure 5 Fore- (top) and hindwing (bottom) base structures of Aphrophora intermedia (Cercopoidea: Aphrophoridae).

Figure 6 Fore- (top) and hindwing (bottom) base structures of Ledra auditura (Membracoidea: Cicadellidae).

Figure 7 Fore- (top) and hindwing (bottom) base structures of Machaerotypus sibiricus (Membracoidea: Membracidae).

Figure 8 Fore- (top) and hindwing (bottom) base structures of Tettigometra bipunctata (Fulgoromorpha: Tettigometridae).

Figure 9 Half-closed forewing base of Meimuna opalifera, showing 1Ax and associated structures. When wings are closed completely or flapped up, the posterior projection of ANWP fits into the concavity of $1 \mathrm{Ax}$ as indicated by arrow.

Figure 10 Forewing base of Meimuna opalifera, showing DMP and associated 
sclerites.

Figure 11 Two equally parsimonious trees estimated from the characters selected from the wing base structure. Two topologies are different only in the relationships within the Cercopoidea. Outgroups are omitted. Character and character state changes reconstructed on the branches are indicated by black bars (nonhomoplasious), black triangles (homoplasious), and gray circles (ambiguous). Numbers in circles indicate Bremer support values (not indicated for BS $=0$ ). 


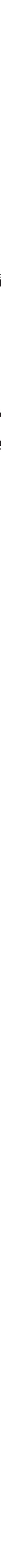




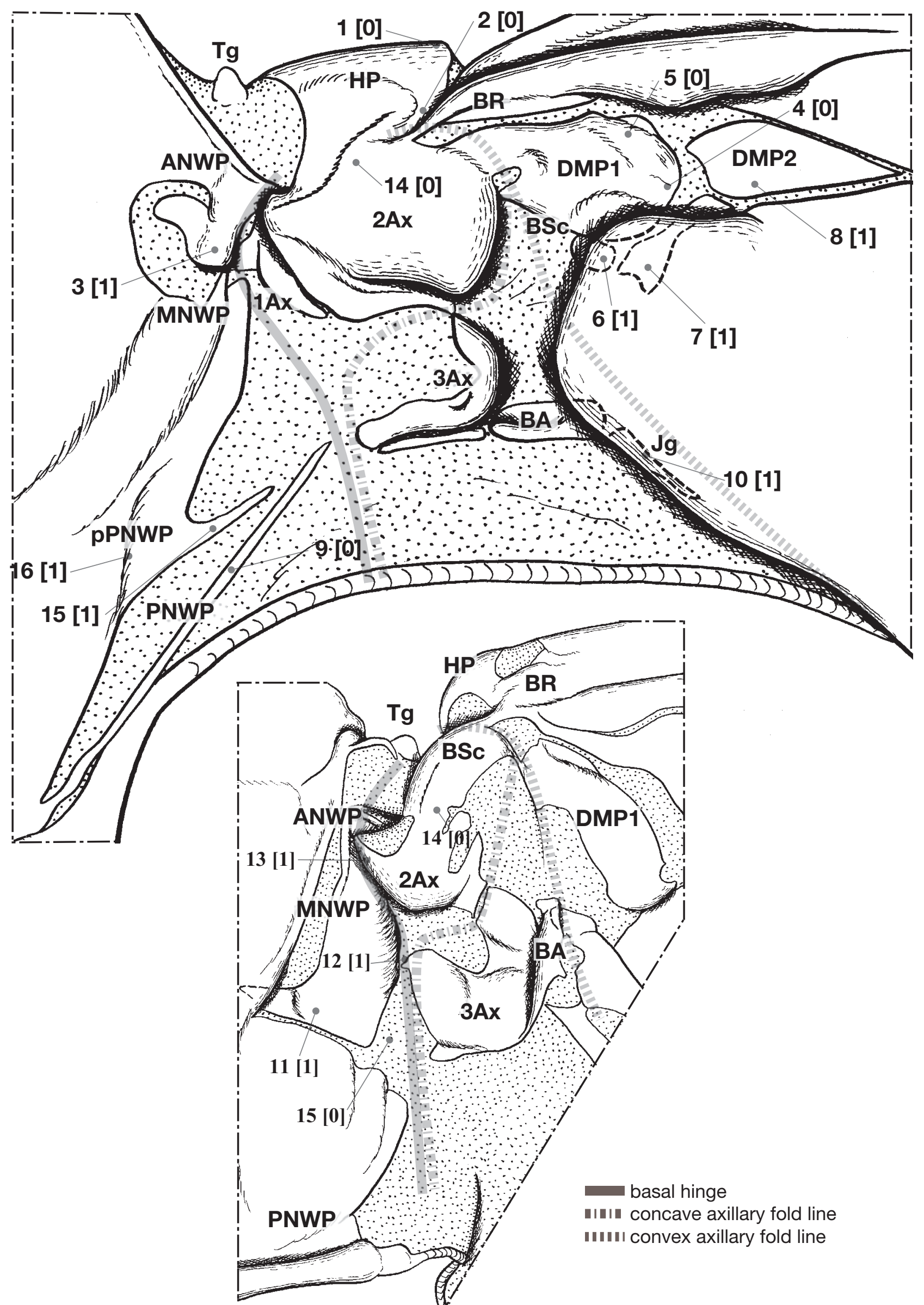




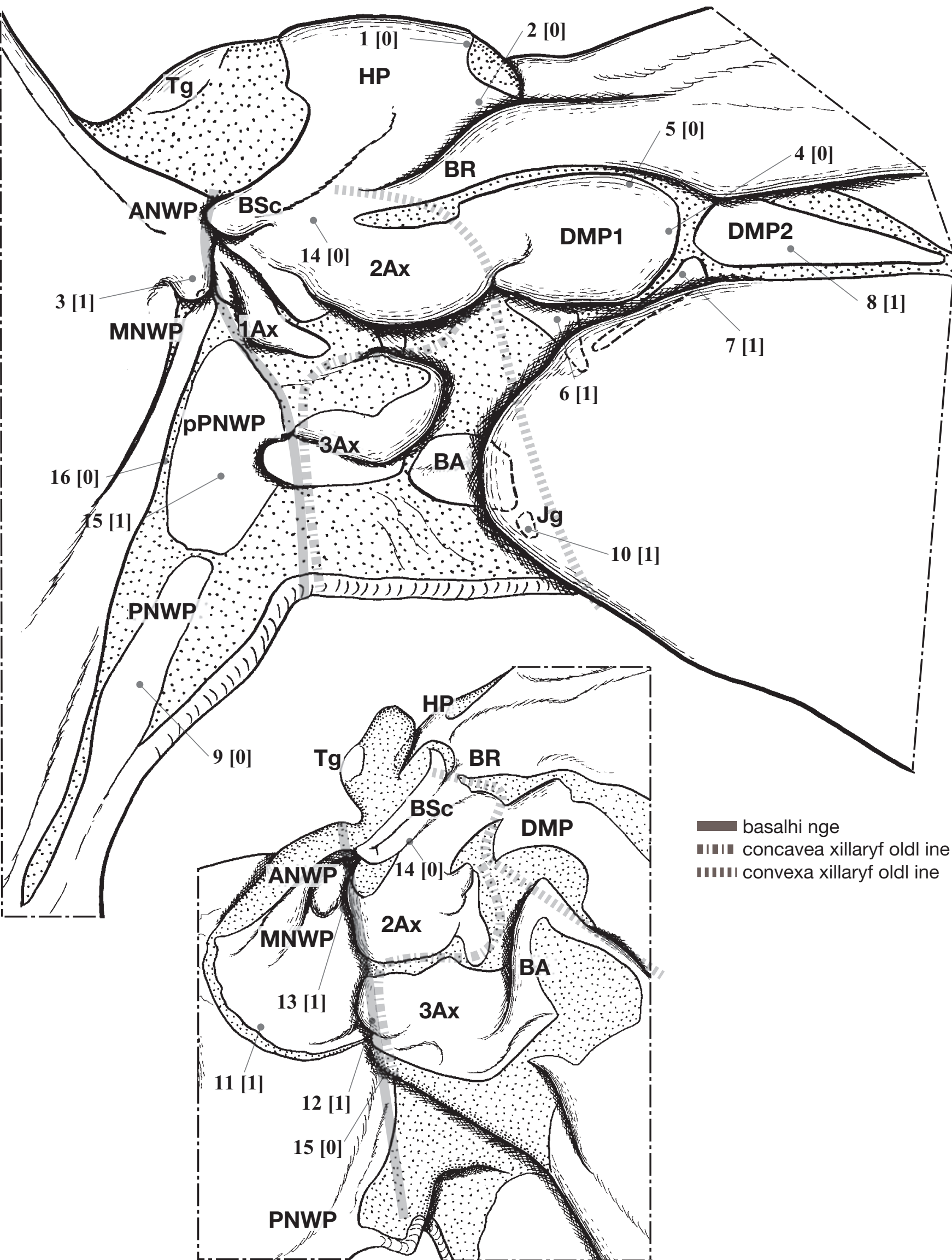




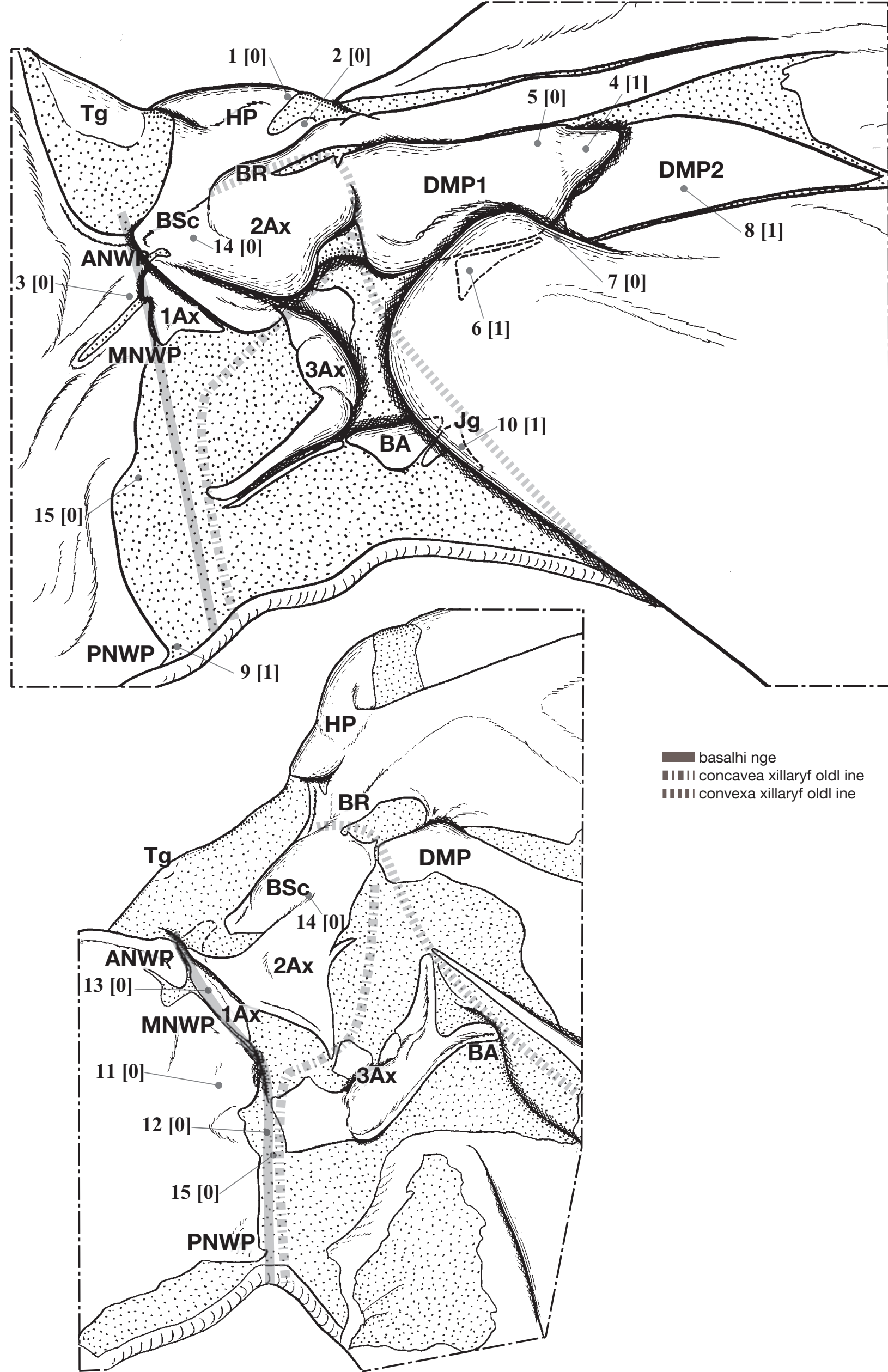





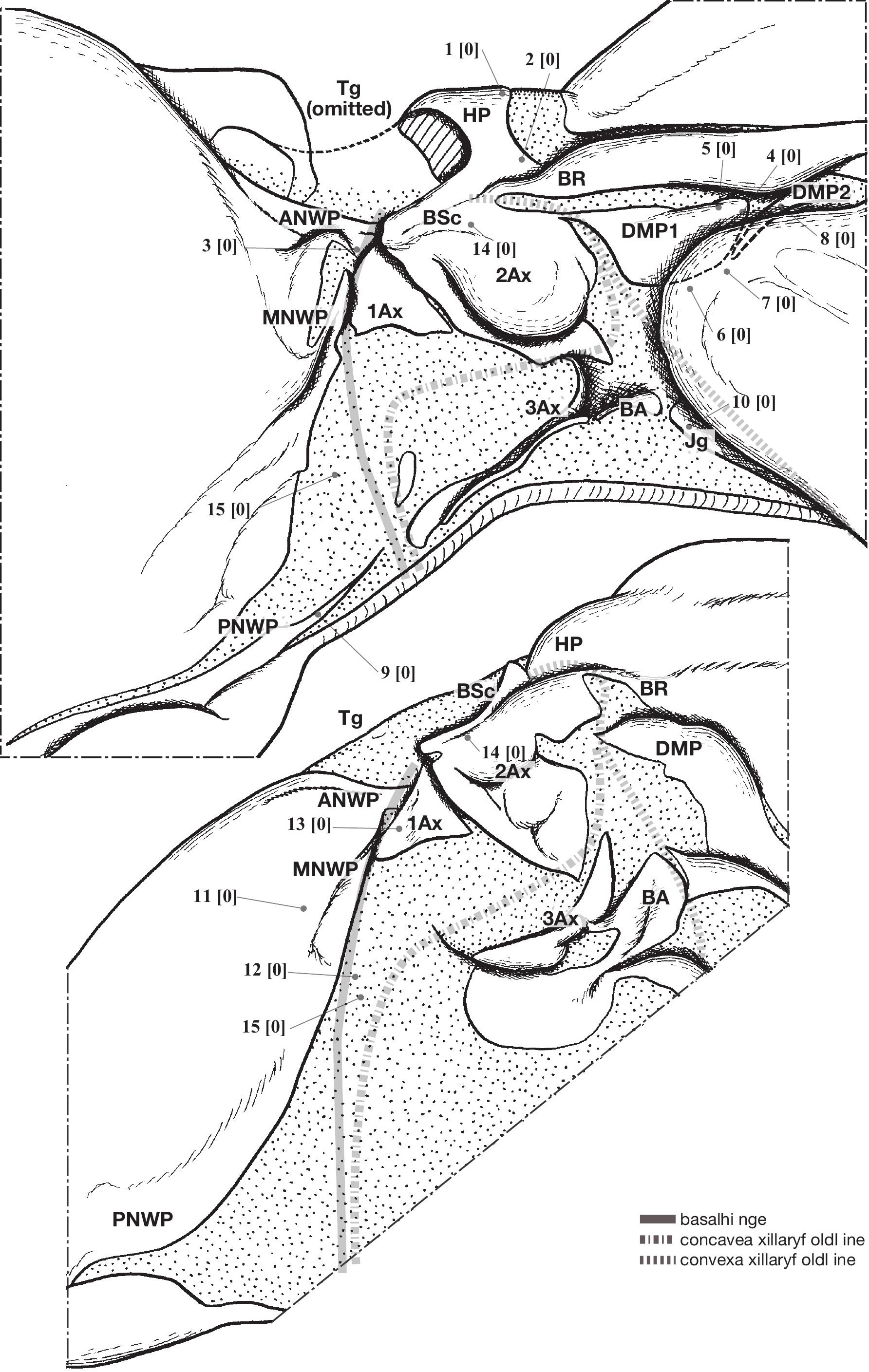




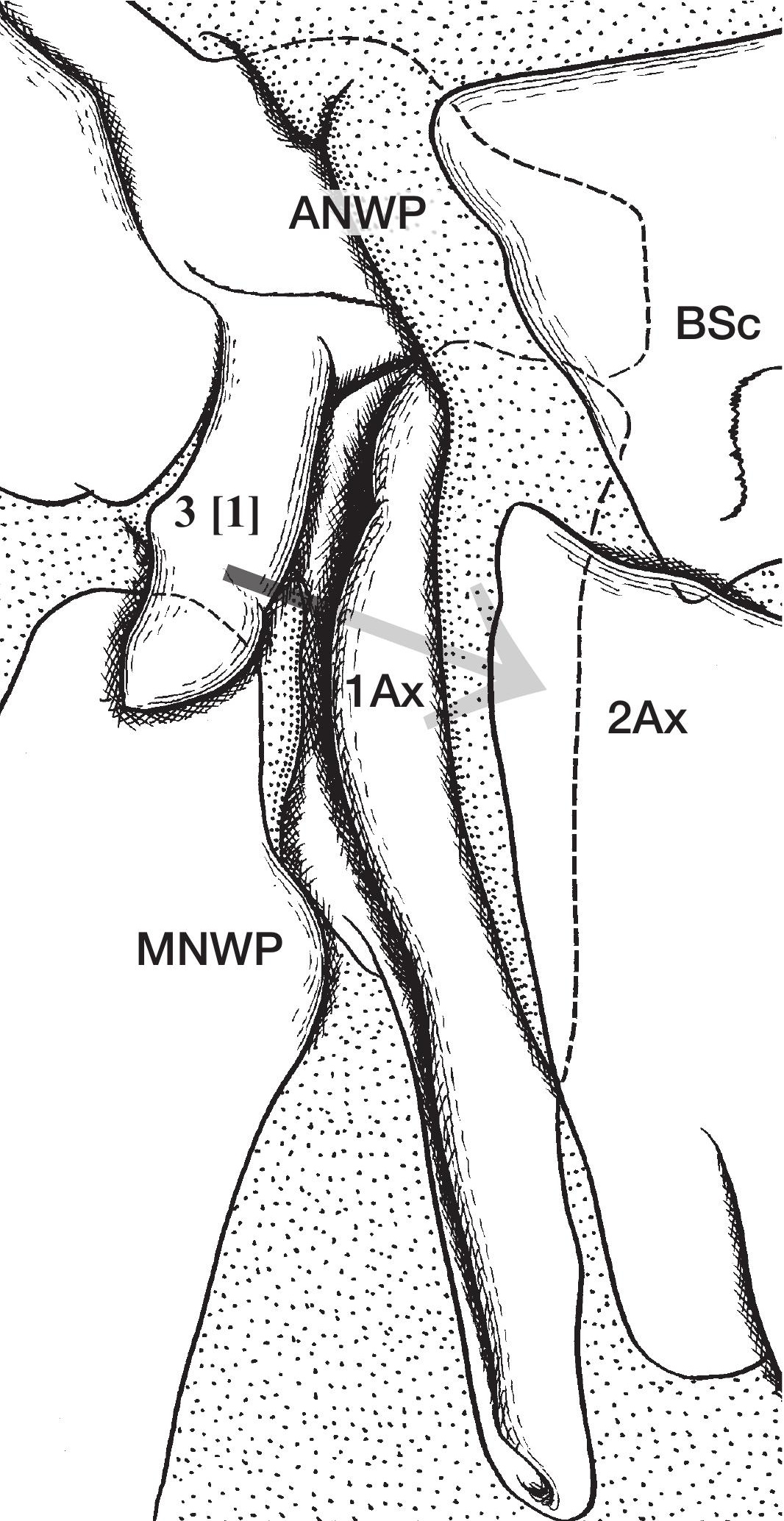




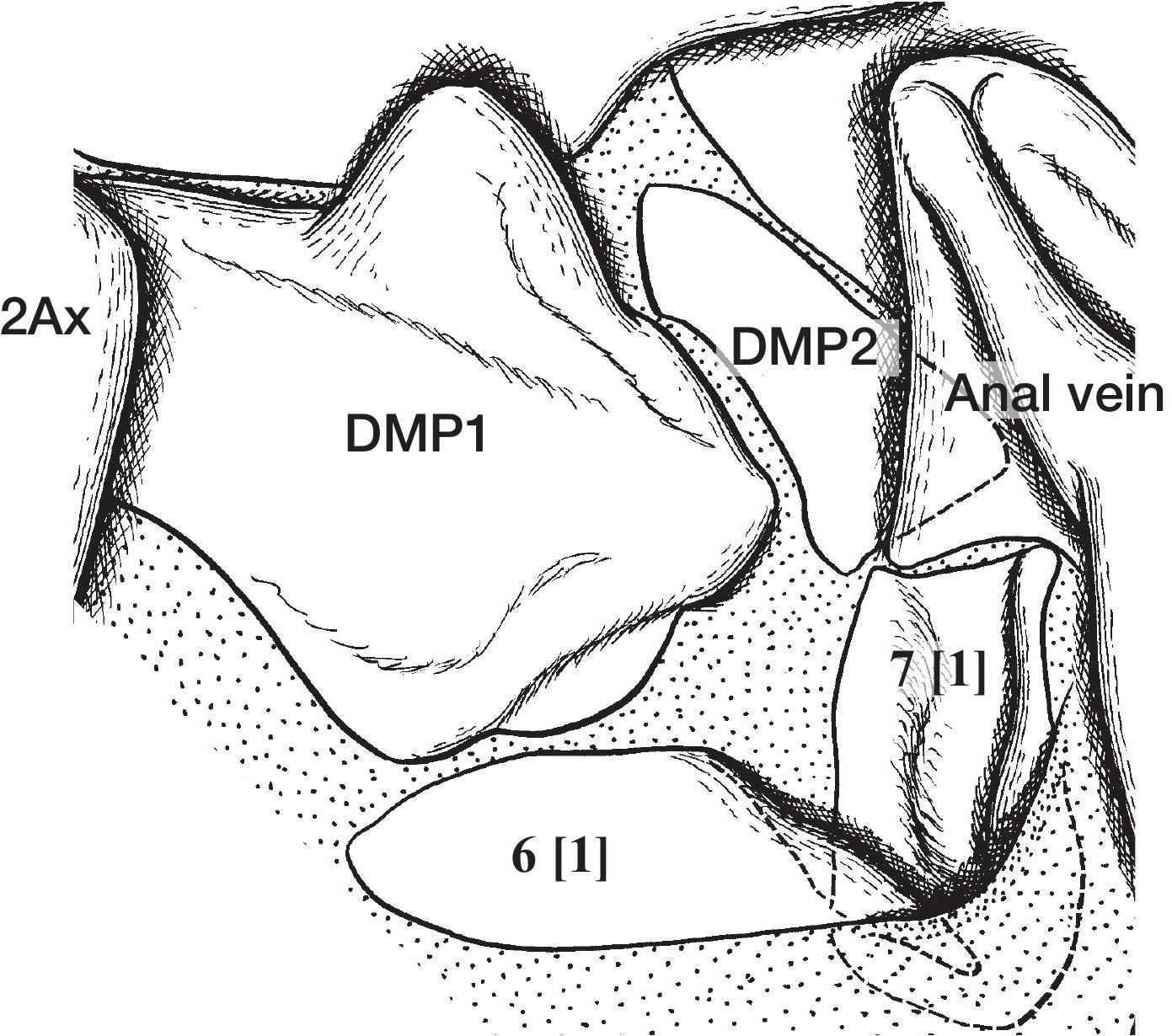




\section{CICADOIDEA}

\section{MEMBRACOIDEA}
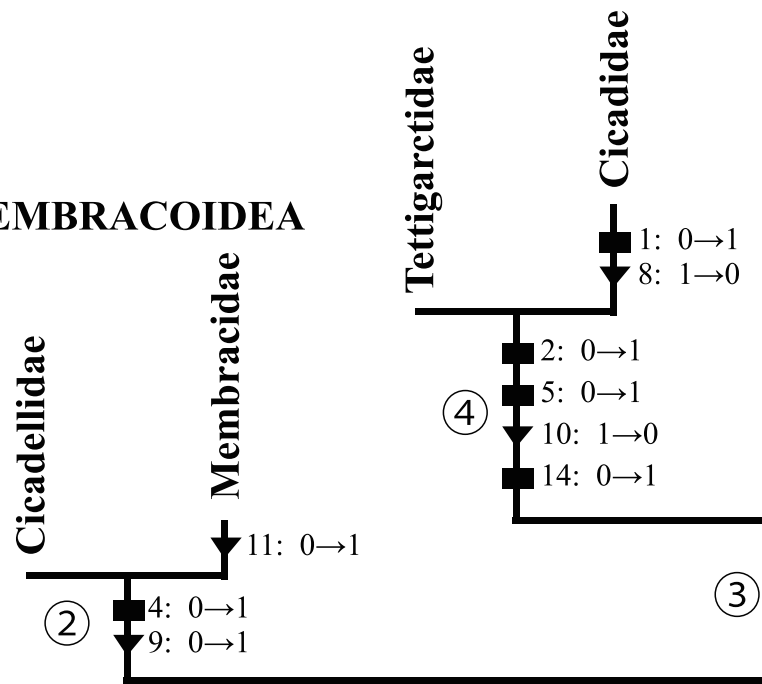

CERCOPOIDEA
(2) $\begin{aligned} & \text { 6: } \\ & \text { 8: }\end{aligned}$
CICADOMORPHA

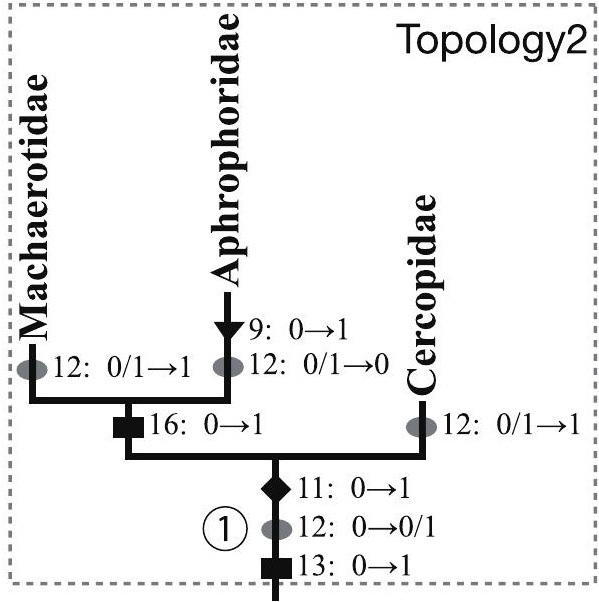


Table 1. Taxa examined for this study.

\section{CICADOMORPHA}

Cicadoidea

Tettigarctidae: Tettigarcta crinita

Cicadidae: Graptopsaltria nigrofuscata, Hyalessa maculaticollis, Meimuna opalifera, Terpnosia nigricosta

Cercopoidea

Machaerotidae: Hindoloides bipunctata, Machaerota takeuchii

Cercopidae: Eoscarta assimilis, Cosmoscarta sp. (Taiwan)

Aphrophoridae: Aphrophora intermedia, Aphilaenus nigripectus, Philagra albinotata Membracoidea

Cicadellidae: Bothrogonia ferruginea, Drabescus sp. (Honshu, Japan), Cicadella viridis, Iassus sp.

(Honshu, Japan), Ledra auditura, Matsumurella praesul, Pagaronia sp. (Hokkaido, Japan), Penthimia nitida, Trocnadella suturalis

Membracidae: Campylenchia sp. (WI, USA), Gargara katoi, Machaerotypus sibiricus, Publilia modesta

\section{FULGOROMORPHA}

Tettigometridae: Tettigometra bipunctata

Cixiidae: Oliarus sp. (Kyushu, Japan)

Issidae: Sarima sp. (Okinawajima, Japan)

Ricaniidae: Ricania japonica

Flatidae: Geisha distinctissima

Achilidae: Catanidia soburina

\section{HETEROPTERA}

Enichocephalidae: Hoplitocoris lewisi

Belostomatidae: Diplonychus japonicus

Coreidae: Paradasynus spinosus

Acanthosomatidae: Acanthosoma denticauda

Pentatomidae: Lelia decempunctata, Pentatoma japonica, Palomena angulosa 
Table 2. Data matrix for the phylogenetic analysis.

\begin{tabular}{llllllllllllllllllll}
\hline Character No & 110 & 10 & 10 \\
\hline Heteroptera & 0 & 0 & 0 & 0 & 0 & 0 & 0 & 0 & 0 & 1 & 0 & 0 & 0 & 0 & 0 & $?$ \\
Fulgoromorpha & 0 & 0 & 0 & 0 & 0 & 0 & 0 & 0 & 0 & 01 & 0 & 0 & 0 & 0 & 0 & $?$ \\
Tettigarctidae & 0 & 1 & 1 & 0 & 1 & 1 & 1 & 1 & 0 & 0 & 0 & 0 & 0 & 1 & 1 & 0 \\
Cicadidae & 1 & 1 & 1 & 0 & 1 & 1 & 1 & 0 & 0 & 0 & 0 & 0 & 0 & 1 & 1 & 0 \\
Cicadellidae & 0 & 0 & 0 & 1 & 0 & 1 & 0 & 1 & 1 & 1 & 0 & 0 & 0 & 0 & 0 & $?$ \\
Membracidae & 0 & 0 & 0 & 1 & 0 & 1 & 0 & 01 & 1 & 1 & 1 & 01 & 0 & 0 & 0 & $?$ \\
Machaerotidae & 0 & 0 & 1 & 0 & 0 & 1 & 1 & 1 & 0 & 1 & 1 & 1 & 1 & 0 & 1 & 1 \\
Cercopidae & 0 & 0 & 1 & 0 & 0 & 1 & 1 & 1 & 0 & 1 & 1 & 1 & 1 & 0 & 1 & 0 \\
Aphrophoridae & 0 & 0 & 1 & 0 & 0 & 1 & 1 & 1 & 1 & 1 & 01 & 0 & 1 & 0 & 1 & 1 \\
\hline
\end{tabular}

